\title{
The Analysis of WeChat based on Network Economics
}

\author{
Xuanyu Piao ${ }^{1, a}$ \\ ${ }^{1}$ Haidian Foreign Language Shiyan School \\ ajerrypark@sina.cn
}

Keywords: WeChat, Network Economics, Network Externalities, Metcalfe Principle, Matthew Law

\begin{abstract}
WeChat is a product that invented by Tencent company, which have a predominant status in Chinese Instant Message market. Research on this application is necessary and valuable. In this article, this application will be analysed by an innovate perspective, which is Network Economics. The analysation is mainly from 4 parts: the brief historical background of this application; the market strategy of WeChat which further include the establishment of a strong installation base, the increasement of the overall transfer cost of this application, the persistence on mobile terminal, and the desire to expand into global market; the value of this application to the Tencent company; and the challenge WeChat facing in the global market.
\end{abstract}

\section{Introduction}

\subsection{The background of the research}

In modern society, technology is developing in an unprecedent rate. The development of internet and network plays a crucial role in overall economics. The traditional industry suddenly has an uncertain future, while industry that mainly concern on internet technology gain great success and showing sign of occupying the whole economics. This trend creates a new academic field, which is network economics. While Facebook and Twitter own a dominating status in the rest of the world, WeChat is a predominant application regarded as a communication utility in China. It is an application that invented by Tencent company owns more than 1 billion users. Though the contribution of this application to the whole economics is remarkable, the research and analysation relevant to this application from the Network Economics is rarely exists. The analysation of WeChat base on Network Economics is significant to comprehend how tech giants is functioning, as well as a better understanding of our modern society. The research and analysation of WeChat will be mainly separated into three parts. In the first part, the characteristics and features of WeChat will be demonstrated, then the market strategy of WeChat will be analysed, finally, the value and the method of revenue acquisition will be exhibited.

\subsection{The Literature Review}

In this Essay, the WeChat will be analysed with an innovate perspective which is from Network Economics. Since Network Economics is an emerging academic realm existed at the end of the twentieth century, it is very necessary to elucidate some basic principles and terms appears frequently in this field.

\subsubsection{Principles of Network Economics}

a. Metcalfe's Law indicates that every time a new user enters the network, the overall value of the network will be enhanced exponentially. For example, provided that $\mathrm{n}$ new users enter a network $\mathrm{B}$, the value enhanced will be equal to $n(n-1)$.

b. the Matthew effect is a phenomenon in a network that the company that are at a predominant status will gain more reputation and accomplishment while the meagre one will have difficulty to gain reputation and achievement, as a result stronger company becomes stronger in the future and the weaker is eliminated by the market.

Both of these principles show the features of Network Economics, which is network externality and positive feedbacks. 


\subsubsection{Network externality and positive feedback}

a. Network externality can be explained by Metcalfe's Law, the meaning is almost identical: the value of a network enhances for every individual in the network when a new individual enters this network. In another word, the bigger the network is, the network is more useful for everyone in the network. As a result, the dependence from users on this network will enhance, which lift the cost of transfer and finally force the users to stay in the original network.

b. Positive Feedback means that in a system, after the variation in the participants, the system will be changed in the same trend. In traditional industry, it is believed that when the number of goods increased, the price of the good in the market will be negatively reflected, which is called negative feedback, opposite with positive feedback. However, in a network, since its own network externality, there will be positive feedbacks.

\section{A brief development history of WeChat}

WeChat is an application that initially invented by Tencent company, which successfully dominated the market using another application called QQ, which shares similarity with WeChat. The premier version of WeChat is incredibly simple, which only include one function: communication using words. This kind of application failed to attract large amounts of users since the function was limited. However, the number of users boosted after WeChat added a new function called voice transmission, this function differed WeChat from other application and provided easement for the communication. From Version 2.0 to Version 4.0, WeChat continuously improved the communication functionality, and the overall amounts of users surged after every update it made. However, the primary function of WeChat is still only limited in communication; this situation has been changed after Version 5.0, WeChat invented a unique function which is WeChat pay, which stimulates online trade and create a lot of convenience that never be owned by other social communication application. By 2018, the active users of WeChat reached 1 billion, that shows that majority of Chinese are using WeChat and WeChat is showing sign of becoming irreplaceable.

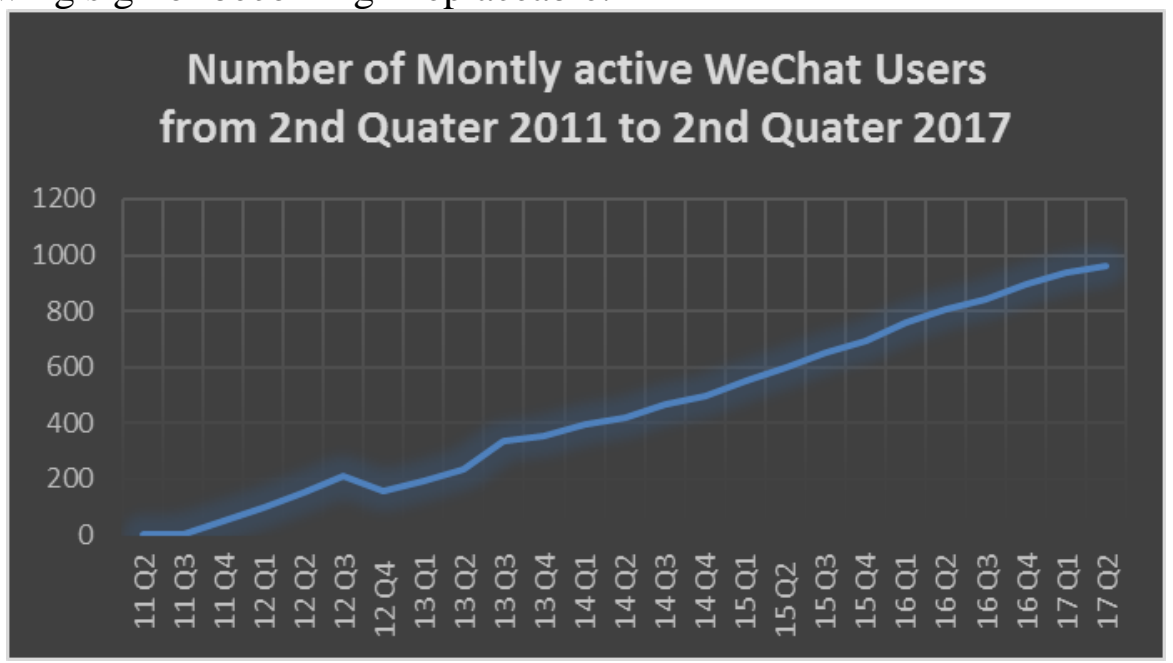

Figure 1: Number of Monthly active WeChat Users from 2nd Quarter 2011 to 2nd Quarter 2017(in million)

Note: The data is come from https://www.statista.com/statistics/255778/number-of-active-wechat-messenger-accounts/

\section{The market strategy of WeChat}

\subsection{Establishment of a strong installation base}

According to the Metcalfe's Law, the value of a network will enhance exponentially. Furthermore, the marginal cost of promoting a network product is equal to zero. As a result, in order to enhance the value of the application and reduce the average cost of application, enhance the installation base was 
regarded as a most important element when they were inventing the application. The Tencent company mainly used two strategy.

First of all, Tencent company decided to make WeChat a free application, so that every individual who have a mobile can access to this application without paying to the company. Since the marginal cost of a network product is zero, the overall revenue of the company will not be jeopardized by the deficit of the cost and profit. Second, WeChat add unique function that other applications do not have, for example drifting bottle and friend circle. These functions makes WeChat shift from a simple communication application to a place that people can meet new friends and express their own ideas. Third, it successfully attracts a wide generation of users by adding WeChat Pay into the application. In order to trade with the young generation, the older generation will have to install WeChat. Hence, the users are more diverse compare to other similar application.

The success of QQ also contributes a significant amount to the installation base of WeChat. In 2011, QQ was the most widespread application which was also a product of Tencent company. Tencent company added a function to WeChat that eliminate the transfer cost of QQ users, which is to relevant the QQ to the WeChat so that the user will not need to add their friends and establish a new friend system after change to WeChat. Furthermore, WeChat also relevant users phone number with its account, so that users can add friend in their address books.

\subsection{Increase the transfer cost of leaving the WeChat}

Before the WeChat dominated the market of China, Tencent company had a lot of competitors that negatively affected the overall user amount. In order to reduce the losses of users, Tencent company use multiple strategies to increase the transfer cost of the users to prevent new users abandon WeChat.

First of all, the pressure of communication enhances the transfer cost of WeChat, the tools that help users get acquainted with new friends potentially enhance the overall transfer cost of the users. Since WeChat have a lot of practical tools that help users establish a larger friend system compare to using other instant message application, the users may need to spend time to reestablish this friend system after using other applications. Furthermore, the prosperity of online games shifts the transfer cost of the young generation to an extreme level. Tencent negotiated and invested on some online game company and they bought part of the copyright. As a result, Tencent modified some of the popular games for example LOL (League of Legend) and PUBG (Playerunknown's Battlegrounds). To start a battle with users' friends, they have to $\log$ in to their WeChat or QQ. An individual who abandon their WeChat account will lose this opportunity which may affect the individual's relationship with his or her friends. According to a survey, PUBG mobile version reached 200 million in China, and $61.9 \%$ of the users is under 25 years old, this data indicates that the online game is becoming one important method for young generation to entertain and communicate 1.

In addition, the convenience of trade brought by WeChat also shifts the transfer cost. Firstly, WeChat Pay creates a new type of economics which is WeChat Business, in this type of business, people trade on WeChat, advertising the product using friend circle. In other kinds of application, the users cannot trade directly in the app, as a result user will lose the opportunity of trading with other. Secondly, some restaurant and online shopping application only support WeChat Pay and Cash, the users who do not have WeChat account can only use cash which is not convenient for the users. Finally, WeChat successfully combines the traditional Chinese culture and modern technology, and they create a function called Red Pocket, this application allows users to transfer money to each other. The one who does not have WeChat account will lose money directly since people will not give them red pocket.

\subsection{WeChat strategy on mobile}

Compared to QQ, WeChat have a great concern on mobile terminal, and WeChat only put limited concerns on the PC. This strategy is benefits to the WeChat since the mobile phones are becoming the most common communication tool instead of laptops or computers simply because the inconvenience

\footnotetext{
${ }^{1}$ Available from: https://www.jianshu.com/p/cf38dc41c71b
} 
caused by the weight and size of the subsequent utilities. The concise interface and the practical function of this application perfectly fit the feature of mobile phone, which will enhance its value to the user and strengthen the installation base.

\subsection{Tencent seize the opportunity provided by the government.}

Chinese government also plays a positive role in the success of WeChat by eliminating the WeChat competitors from abroad which have practical function and already dominate the global markets. Chinese government banned those kinds of application and block them with special technique, which can be only defeated using VPN, however, Chinese government also illegalize VPN in the country. As a result, WeChat can easily establish a monopoly in the Chinese IM market.

\subsection{The market strategy of WeChat in global market}

Different with all the products of Tencent, WeChat is expected to occupied the global market by the company. In order to reach the goal, company uses multiple strategy to make WeChat to adapt foreign market. First of all, Tencent give WeChat a more localize name. Previously, WeChat had never owned an English name, the name in English is Weixin, simply translated from the pronunciation of WeChat in Chinese, which will cause difficulties for foreigner to read and to remember the products. Furthermore, the application can be used in multiple language, not only Chinese but English, Arabic, Korean and multiple other languages. Most importantly, when foreign company is attempt to trade with Chinese company, WeChat can be a very practical tool because of the effective translation function in the application. Finally, advertisement bombard is also a strategy Tencent used in abroad but rarely used in China. The reason is that Tencent is not regarded as well known in the abroad while in Tencent home country, it is already a famous company

\section{4. the challenge WeChat is facing in global market}

Although Tencent company is enjoying the great fruition it obtains in China, the globalization process of WeChat is stumble and bumpy all the way. With the help of the advertisement, Tencent company gains subtle success in the Southeast Asia and India. However, failed to dominated any single market expect Chinese mainland, because WeChat has notable defects compared to other application abroad, which caused the failure of WeChat abroad.

First of all, the most practical feature of WeChat in China is WeChat Pay, people can easily trade by connecting their credit card with their WeChat account. Unfortunately, WeChat Pay do not support most of the foreign types of credit card, which mean customer from abroad cannot use them. Furthermore, most of the restaurants and stores outside the China mainland do not support the WeChat Pay, as a result WeChat Pay cannot be considered as a practical function abroad and WeChat loses its biggest advantage compared to other application.

Second, according to the Matthew Law, because of the network externality, the application with larger installation base will gain more users while the application with weaker installation base will be eliminated. A noteworthy fact is that when WeChat entered the global market, WhatsApp and Facebook have already dominated the majority of the market so WeChat cannot attract the user because of the transfer cost, as a result they cannot gain success 2 .

\section{The revenue of Tencent company}

Since WeChat is a free application, Tencent company gain revenue from multiple ways that is different with traditional business. Research and analyzation on the revenue of this application become very significative to know the operation of Network Economics. The revenue of Tencent company earned from WeChat is mainly relied on three methods.

Firstly, mobile games and online games help Tencent company gain major part of its interest. In 2017 Q1, the overall revenue of Tencent company was 49.5 billion RMB, while the revenue of

\footnotetext{
${ }^{2}$ Available from: http://tech.163.com/14/0220/14/9LHJCMSR00094NPU.html
} 
mobile game was 12.9 billion RMB. The high revenue of mobile game is depending on huge installation base of WeChat since the WeChat users can start a battle very easily3. The revenues of games continuously occupied a high percentage in the overall income.

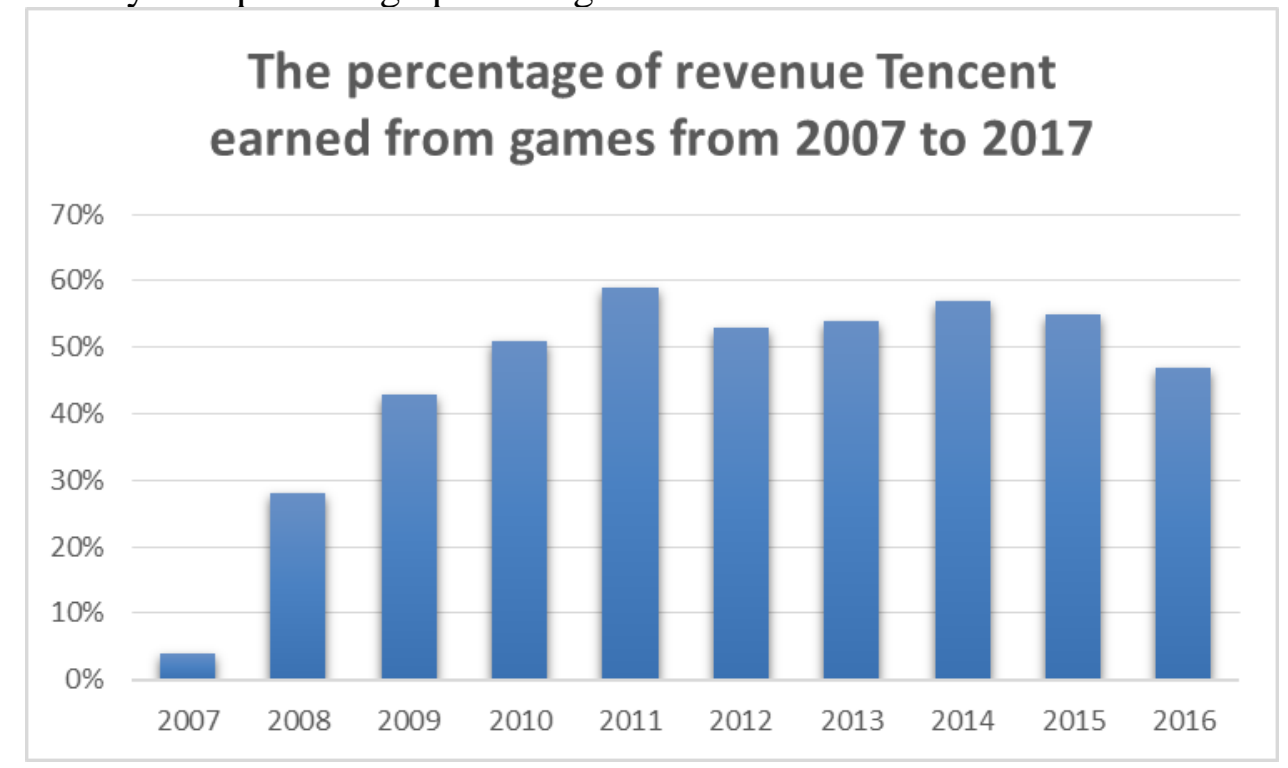

Figure 2: The percentage of revenue Tencent earned from games from 2007 to 2017

Note: The Data is from 《the analysis of Game Industry in China》, 2017.

Secondly, advertisement plays a critical role in the overall revenue of Tencent company, in 2016, $18.44 \%$ of the revenue is come from advertisement, while in 2005 , it was only about $7.9 \%$. The strong installation base of WeChat positively affects the overall revenue of advertisement since more trader prefer to advertise on the WeChat. However, the revenue from advertisement are still unsatisfied compared to other application abroad. For instance, 95\% of revenue of the Facebook company is come from advertisement.

Thirdly, Tencent company also earn part of the money from WeChat Pay. Tencent company will take small portion on money each time users trade on the application or use WeChat Pay. The revenue from WeChat Pay, however, remains tiny since Tencent only take 1/1000 of the overall trade.

Finally, WeChat also provide a strong installation base for other application of Tencent invented in the future, as a result, Tencent company could continuously monopoly the social communciation market in China. In addition, it also ensures the revenue of other application of Tencent company and increases the competitive power of this company.

\section{Conclusion}

In the research, the market strategy that thrives the WeChat, the problem WeChat is facing, and the value of WeChat to Tencent company have been analyzed. WeChat is an application gaining great success in China because of its enormous installation base contributed by QQ and unique function that never owned by any other application in China, however, in order to be a greater company, Tencent company have to promote their products into foreign market. The main reason that WeChat failed to do that is WeChat cannot attract a large installation base because the function that considered practical in China is no longer useful in foreign country. In order to make Tencent company to become an international company and globalize the WeChat, Tencent company may corporate with the big local stores and makes WeChat Pay a practical utility abroad. Furthermore, the increasing trade between China and foreign countries can be an opportunity for Tencent company since WeChat

\footnotetext{
${ }^{3}$ Available from: http://games.qq.com/a/20170517/040773.htm
} 
is the only feasible way of communication with Chinese people with . Furthermore, Tencent company should pay more attention on the user's privacy since foreign users attach great importance on their privacy and Tencent company have to prove that their product is safe to use.

All in all, although WeChat is regarded as the most successful IM application in China, it still needs a lot of improvement to adapt international market.

\section{Reference}

[1] Haiyan. Zhang, Hunan University of Science and Technology, The explanation of free digital products from Network Economics perspective, $[\mathrm{J}]$ Theory and Practice of Contemporary Education, 2012(1)

[2] Zequan. Zhang, Dongbei University of Finance and Economics, The analyzation of Tencent company base on Network Economics, 2006(5)

[3] Tao. Wang, Hanlei. Liu, Changchun University of Technology, The current situation of WeChat and the analyzation of its trend, $[\mathrm{J}]$ The discovery and observation

[4] Yongfeng. Li, Inner Mongol Normal University, The analyzation of growing WeChat users, [J] New Media

[5] Yaping. Jiang, Shanghai Normal University, Research on Diffusion of WeChat Based on Bass-BP Combination Model, 2007

[6] Chuanzhong. Du, Zhipeng. Liu, Nankai University, Users Subsides and Money Burning of Internet Startups: Legitimate Competition or Seeking Monopoly, 2017

[7] Yan. Zhou, Renmin University of China, The Basic Theory of Network Economics and the Feature of Network Economics, 2015

[8] Zhiliang. Xiao, Wuhan University, Analysis on the Operation of Publisher's Digital Products Based on Network Economics, 2018 